\title{
THE EFFECT OF COD LIVER OIL ON GROWTH IN A CASE OF "INTESTINAL INFANTILISM" *
}

\author{
L. EMMETT HOLT, M.D., LL.D., ANGELIA M. COURTNEY \\ AND \\ HELEN L. FALES \\ NEW YORK
}

Greatly retarded growth, amounting to a condition of infantilism, is occasionally seen as a result of certain prolonged derangements of the functions of digestion, as well as a consequence of organic changes in these organs. The exact nature of the changes which bring about arrested growth in the first mentioned group of cases is as yet little understood, but it has generally been connected with disturbances in the metabolism of calcium, magnesium and phosphorus. Negative balances in these substances have repeatedly been found in children belonging to this class.

Because of the demonstrated effect of cod liver oil in increasing the retention of these inorganic salts in other conditions, particularly in rickets, it was determined to try its effect on the patient whose history is herre reported, in whom the diagnosis of infantilism of intestinal origin was tentatively made.

\section{REPORT OF CASE}

History.-Elizabeth R., aged 81/2 years, came first under observation Feb. 9, 1916; her condition may be described in a word as "infantile," her weight being but 29 pounds net and height $391 / 8$ inches, or that of an average child of about 3 years. She was the eldest of three children, the other two being normal and well developed, a sister of 6 years being 4 inches taller and 12 pounds heavier than the patient. The parents were healthy and lived in a suburban town in excellent surroundings. The child had always had the best of home care.

Early progress was quite normal. She was born at term, weighing 8 pounds; was nursed for twelve months and did very well; muscular development was average. Weaning was easy and feeding for the second year not at all difficult. In fact, up to nearly 2 years of age, except that her stools were much of the time very pale, her progress was considered satisfactory. The food given at that time was chiefly milk, about 50 ounces being taken daily in five meals; she was also given beef juice, eggs and orange juice.

Ever since she was 2 years old the child had suffered from digestive symptoms, though she had never had acute attacks either of diarrhea or dysentery. Occasional vomiting was present during the first two years, but after that time vomiting attacks became more frequent, recurring every few days, and very

* Submitted for publication May 28, 1917.

* From the Laboratories of the Babies' Hospital and the Rockefeller Institute for Medical Research.

* Read at the meeting of the American Pediatric Society, White Sulphur Springs, W. Va., May 28, 1917. 
often she would vomit during the night. The stools were always pale and were reported large in proportion to the food taken; at times she was constipated, but much of the time the stools were reported "frothy" in character, but no blood and rarely much mucus was present. There was always much gas in the bowels. Abdominal distention had been an almost constant symptom and most of the time it was extreme.

The diet had been much restricted. From the end of the second year milk had been excluded, also green vegetables, soups, cereals and fruits. Until a few months before her visit she had been fed chiefly on rare meat, eggs, toast and butter and a large amount of potato. For the last few months small quantities of milk had been added to the diet. The appetite was usually fair, but she constantly craved highly seasoned food and such articles as onions, strawberries, ice cream, lemons, green corn, etc.

The child had never had any acute illness except an attack of grip a few weeks before. Her progress mentally had been nearly that of the average child. On the whole, the mother considered her condition as rather better for the preceding six or eight months than previously, the abdominal distention had been much less and the stools of better character, but vomiting still occurred about twice every week.

No records of the weights had been kept; the following were given by the mother from memory:

At 12 months, 19 pounds; 3 years, 241/2 pounds; 4 years, 30 pounds; 8 years, $301 / 2$ pounds (her best weight).

There were also no records of her height, but the mother thought that for the preceding two or three years there had been little or no growth.

Physical Examination.-On examination she appeared physically like an average child of 3 or $3 \frac{1 / 2}{2}$ years. The body was thin, but was in no sense wasted. The child was symmetrically small-trunk, face and extremities. The head was well formed and showed no irregularities or abnormalities; fontanel closed. Hands and feet, legs and arms were quite normal ; facial expression, intelligent; speech and mental development were like that of an average child of 6 or 7 years. Physical examination of heart and lungs was negative. The circulation was rather poor; extremities much of the time cold. In the abdomen were found no abnormal masses; there was no distention. The liver and spleen were not palpable. Superficial glands were slightly enlarged. The tongue was coated; the breath now, and usually, sweet; the temperature was normal. There was moderate beading of the ribs, and very slight epiphyseal enlargement, but no signs of active rickets were present. The teeth, twenty in number, were in poor condition; several were carious.

Measurements: Weight, 29 pounds net; height, 391/8 inches; head, circumference, 191/4 inches; chest, circumference, 20 inches.

Though she had suffered almost constantly from digestive symptoms since 2 years old, there did not seem to be in the diet a sufficient explanation for the arrested growth.

Metabolism Observations.-February 27 the child entered the Babies' Hospital for metabolism observations. She was given the same diet in variety and amount which she had been taking for several weeks previously. Though the quantity of food was small, it was all she would take at the time. The diet was as follows:

Breakfast: One egg; 2 slices toast; $2 \mathrm{gm}$. butter; $2 \mathrm{gm}$. sugar; one-half gm. salt.

Dinner: Scraped beef, $60 \mathrm{gm}$; 15 c.c. beef juice; one-half small baked potato; 120 c.c. milk; 2 gm. sugar; 1 gm. salt.

Supper: Toast, one-half slice; 120 c.c. milk; 2 Huntley \& Palmer breakfast biscuits; $2 \mathrm{gm}$. butter; $2 \mathrm{gm}$. sugar.

Was given 60 c.c. water at each meal and all she would take between meals. Total calories in her food, 650 . 
Weight on beginning metabolism observations was 12.5 kilos (271/2 pounds); she was thus receiving at this time but 52 calories per kilo.

In Table 1 are given the average daily intake and excretion for the three days of metabolism observations.

TABle 1.-Metabolism Observations, First Period-Feb. 23-26, 1916

\begin{tabular}{|c|c|c|c|c|c|c|c|c|c|}
\hline & \multicolumn{9}{|c|}{ Grams, Daily Average } \\
\hline & $\begin{array}{l}\text { Nitro- } \\
\text { gen }\end{array}$ & Fat & $\mathrm{CaO}$ & $\mathrm{MgO}$ & $\mathrm{P}_{2} \mathrm{Ot}_{\mathrm{z}}$ & Cl & $\mathrm{K}_{2} \mathrm{O}$ & $\mathrm{Na}_{2} \mathrm{O}$ & $\begin{array}{c}\text { Total } \\
\text { Ash }\end{array}$ \\
\hline Intake... & 5.8398 & 24.176 & 0.5049 & 0.1802 & 1.3052 & 1.4279 & 1.4438 & 0.8593 & 5.4532 \\
\hline Excreted in feces... & 0.7551 & 11.218 & 0.7043 & 0.1525 & 0.7219 & 0.0655 & 0.5075 & 0.0534 & 2.2425 \\
\hline Absorbed........... & 5.0847 & 12.958 & -0.1994 & 0.0277 & 0.5833 & 1.3624 & 0.9863 & 0.8059 & 3.2107 \\
\hline Excreted in urine... & 4.2200 & $\ldots \ldots$ & 0.0181 & 0.0582 & 0.7149 & 1.2212 & 0.6523 & 1.0638 & 3.5802 \\
\hline Retained... & +0.8647 & 12.958 & -0.2175 & -0.0305 & -0.1316 & +0.1412 & +0.2840 & -0.2579 & -0.3695 \\
\hline $\begin{array}{l}\text { Per cent. of intake } \\
\text { retained.......... }\end{array}$ & 14.77 & 53.65 & $\underset{43.1}{*}$ & $\underset{-16.9}{ }$ & $\ldots \ldots .1$ & 9.88 & 19.7 & -30.0 & $\underset{-6.77}{4.78}$ \\
\hline
\end{tabular}

Dried weight of feces, average daily, $18.53 \mathrm{gm}$.

On this restricted diet the child had relatively large, constipated, but welldigested, stools. The metabolism balances showed a fair nitrogen and fat retention, but a very striking loss in mineral salts, only potassium and chlorin showing a positive balance. The abnormal loss took place chiefly through the feces.

For how long a period such a disturbance of salt metabolism had existed it was of course impossible to say, but the negative balances found coincided with the clinical history of the case. Something which would aid in the absorption of salts, particularly calcium and phosphorus, or lessen their excretion through the intestine was evidently what was needed. Even though there were no evidences of active rickets, it was decided to try the effect of cod liver oil as soon as the condition of the digestive organs warranted it, and at the same time to increase the salt intake by giving more food, particularly more milk.

At the end of a month the mother reported that the child had vomited but twice, that she was eating much better and was now able to take besides her other food, 360 c.c. of milk daily. The bowels were now quite regular. Cod liver oil with maltine (a preparation containing 30 per cent. oil) was begun about April 1, 1 teaspoonful twice daily, the dose being gradually increased until at the end of a few weeks she was taking 2 teaspoonfuls three times daily, this being equivalent to about 8 c.c. of the pure oil daily. This amount was continued up to the end of August, a period of about five months. It was then omitted for two months.

In June, July and August she suffered from a moderate attack of whooping cough. During this period the appetite was poor, but she "took her food as a duty," the mother reported. In spite of these adverse conditions the gain in weight was steady, so that by the end of August she was 5 pounds above her low weight early in March. With the subsidence of the whooping cough the appetite returned and her gain in weight was now rapid. The net weights during the summer were as follows:

June $9,31^{1 / 2}$ pounds; August $25,32 \frac{1}{2}$ pounds; September $28,36 \frac{1}{2}$ pounds; November 1, 40 pounds.

The diet was practically the same as that mentioned above, except that the milk had been increased to 500 c.c. daily. Much difficulty was experienced in making her take vegetables; the only one she would take was carrots. 
The next opportunity for an examination of the child was on November 10 . Her measurements were as follows:

Weight, $41 \frac{1 / 4}{4}$ pounds; height, $41 \frac{1}{2}$ inches; head, circumference, $193 / 4$ inches; chest, circumference, $22 \frac{1}{2}$ inches.

This represented a gain in nine months of $2 \frac{3}{8}$ inches in height and of $2 \frac{1}{2}$ inches in circumference of chest, and in weight of $13 \%$ pounds in eight and a half months. The improvement in the general condition was striking; though still very small, she was plump and well nourished; the tongue clean; the abdomen slightly distended; the circulation excellent. She was able to walk a mile a day.

For three weeks during the latter part of November, with an attack of bronchitis, the appetite was lost and her digestion was considerably upset; she vomited occasionally; the bowels became loose and the same light colored "foamy" stools previously mentioned returned. In this attack she lost nearly 4 pounds in weight.

December 12 she entered the hospital a second time for metabolism study; observations were continued for a three-day period, beginning December 15 . Her weight on admission was 37 pounds 6 ounces. The body was well nourished; color good; child good natured and happy; very much more active than during her previous admission. Her stools were formed, in fact, rather constipated, a daily enema being required; they were of a grayish-yellow color, but well digested.

She continued on the same diet which she had been taking at home, which was as follows:

Breakfast: One egg on 1 piece of toast, thinly buttered; 200 c.c. milk; 11/2 slices graham bread and butter.

Dinner: Graham bread, 11/2 slices, with butter; 2 tablespoonfuls scraped beef ; 1 small baked potato with 1 ounce beef juice; 200 c.c. milk.

Supper: One slice white and 1 slice graham bread with butter; 200 c.c. milk.

Two teaspoonfuls of cod liver oil with maltine were, as before, given after each meal. Total calories given estimated at 1,030, making 61 per kilo or 28 per pound.

The intake, excretion and balances for this metabolism period are given in Table 2.

Table 2.-Metabolism Observations, Second Period-Dec. 15-18, 1916

\begin{tabular}{|c|c|c|c|c|c|c|c|c|c|}
\hline & \multicolumn{9}{|c|}{ Grams, Daily Averuge } \\
\hline & $\begin{array}{l}\text { Nitro- } \\
\text { gen }\end{array}$ & Fat & $\mathrm{CaO}$ & MgO & $\mathrm{P}_{2} \mathrm{O}_{5}$ & $\mathrm{Cl}$ & $\mathrm{K}_{2} \mathrm{O}$ & $\mathrm{Na}_{2} \mathrm{O}$ & $\begin{array}{c}\text { Total } \\
\text { Ash }\end{array}$ \\
\hline Intake............. & 8.5701 & 43.382 & 1.3283 & 0.3821 & 2.6311 & 3.4650 & 2.3624 & 2.6159 & 11.9358 \\
\hline Excreted in feces... & 1.4090 & 14.642 & 1.0994 & 0.3163 & 0.7450 & 0.1586 & 0.5841 & 0.2560 & 3.5217 \\
\hline Absorbed........... & 7.1611 & 28.740 & 0.2289 & 0.0661 & 1.8861 & 3.3264 & 1.7783 & 2.3599 & 8.4141 \\
\hline Excreted in urine... & 5.3300 & $\ldots \ldots$ & 0.0174 & 0.0513 & 1.3950 & 2.7840 & 1.0312 & 2.1192 & 6.7092 \\
\hline Retained............ & 1.8221 & 28.740 & 0.2115 & 0.0148 & 0.4911 & 0.5424 & 0.7471 & 0.2407 & 1.7049 \\
\hline $\begin{array}{l}\text { Per cent. of intake } \\
\text { retained........... }\end{array}$ & 21.3 & 66.3 & 15.9 & 3.87 & 18.6 & 15.65 & 31.6 & 9.2 & 14.3 \\
\hline
\end{tabular}

Dried weight of feces, average daily, $31.5 \mathrm{gm}$.

This showed, as compared with Table 1 , a somewhat increased retention of nitrogen and fat; but the most striking changes were in the salt balances. Instead of a negative balance in total ash of 6.77 per cent., there was a positive balance of 14.3 per cent. All the salts showed positive balances. The most marked changes were in the calcium where a negative balance of 43.1 per cent. was changed to a positive balance of 15.9 per cent. 
Six weeks after leaving the hospital, in spite of intercurrent varicella and a mild otitis, the mother reported that she had never known her in better health; she had regained her weight lost during the bronchitis. A report late in March stated that she was in excellent condition except slight stiffness of the legs (rheumatism?) which she had suffered from in previous cold seasons.

The effect of cod liver oil and phosphorus in increasing the calcium and phosphorus retention in rickets has been known for a number of years. The careful observations of E. Schloss, ${ }^{1}$ Schabad, $^{2}$ Birk $^{3}$ and many others ${ }^{4}$ have established this fact beyond question. It has been repeatedly noted in our own observations at the Babies' Hospital. In a recent case the figures for the per cent. of the intake of the different salts absorbed and retained were as follows:

\begin{tabular}{|c|c|c|c|c|c|c|}
\hline \multirow{3}{*}{$\begin{array}{l}\text { Before cod liver oil } \\
\text { and phosphorus.. } \\
\text { After cod liver oil } \\
\text { and phosphorus... }\end{array}$} & \multicolumn{2}{|c|}{$\frac{\mathrm{CaO}}{\text { Absorbed Retainec }}$} & \multicolumn{2}{|c|}{$\begin{array}{c}\mathrm{P}_{2} \mathrm{O}_{5} \\
\text { Absorbed Reta }\end{array}$} & \multicolumn{2}{|c|}{$\begin{array}{l}\mathrm{K}_{2} \mathrm{O} \\
\text { sorbed Retained }\end{array}$} \\
\hline & 16.6 & 14.0 & 51.5 & 18.0 & 74.2 & 12.9 \\
\hline & 45.1 & 43.8 & 88.3 & 33.0 & 87.3 & 23.8 \\
\hline
\end{tabular}

The value of the phosphorus in the combination is questioned by Schloss, though Schabad considers it important. Exactly how it is that the cod liver oil acts, has not yet been clearly shown. It certainly creates conditions which allow the calcium intake to become incorporated into the organism.

From Schloss' observations it would seem to be essential that there should be ample intake of calcium in order to obtain benefit from the cod liver oil. He found, for instance, that with a rachitic breast-fed infant the administration of cod liver oil and phosphorus did not improve the condition; but that when calcium acetate was added great improvement followed. It is undoubtedly true that the intake may be low in some breast-fed infants; but it is almost always adequate in those who are artificially fed.

In a later communication, Schloss states that calcium-phosphorus preparations alone with breast feeding are almost as effective in improving the calcium and phosphorus balances as when they are used with cod liver oil. The simple inorganic salts, he believes, added to breast milk as a food, work better than the natural salts of cow's milk, even when cod liver oil is added. His conclusion is that the nature of the food and the condition of absorption in the body are of even more importance than the form of salt addition.

In the patient under consideration there were but slight evidences of old rickets and none whatever of any active rickets. The cod liver

1. Schloss, Ernst: Jahrb. f. Kinderh., 1913, 28, 694.

2. Schabad, J. A.: Monatschr. f. Kinderh., 1911, 9, 659; 10, 12; 1912, 11, 4.

3. Birk, W.: Monatschr. f. Kinderh., 1909, 7, 450.

4. Review of Rickets. Berl. klin. Wchnschr., 1916, 50, $1340 ; \mathbf{5 1}, 1366$. 
oil was administered with the hope, but without very much expectation, that it might influence salt retention. At the same time, by increasing the diet, especially the amount of milk, an attempt was made to increase the salt intake. The results in this case far exceeded our expectations and they showed conclusively how essential to proper growth is the assimilation of the salts ingested.

There are certainly several factors that must be considered in explaining the improvement in this patient. An improved digestion from the omission of certain disturbing articles of food, an enlarged diet, particularly the addition of the milk, the cod liver oil, and possibly the preparation of malt with which it was administered - any one or possibly all of these were factors in the result. It is our own belief that the cod liver oil was by far the most important one, the next being the milk.

Whether children like the one whose history is here given are likely to reach a normal physical development, is a question of great interest. We know from the studies of Osborne and Mendel on rats that growth may be arrested by deficient feeding for very long periods, and then by proper feeding, growth and development may be resumed until the normal is reached. They found, however, that there was a period beyond which, if the deficient feeding was continued, growth was not resumed. There are, then, certain limitations to growth which cannot be exceeded. All children like this one need to be closely watched, and, if possible, metabolism observations made from time to time to determine the result of the feeding. 